\title{
Using decades of spawning data and hydraulic models to construct a temperature-dependent resource selection function for management of an endangered salmonid
}

\author{
Peter N. Dudley, Sara N. John, Miles E. Daniels, and Eric M. Danner
}

\begin{abstract}
In North America, impassable, man-made barriers block access to salmonid spawning habitat and require costly restoration efforts in the remaining habitats. Evaluating restored spawning habitat quality requires information on salmon water velocity and depth preferences, which may vary in relation to other variables (e.g., water temperature). We demonstrate a generalizable, low-cost method to gather and analyze these data by combining aerial redd surveys of winter-run Chinook salmon (Oncorhynchus tshawytscha), 2D hydraulic modeling, and generalized linear models to calculate spawning resource selection functions (RSFs). Our method permits the examination of interactions between environmental variables and habitat selection, which are frequently treated as independent. Our methods resulted in an RSF that shows interactions between both velocity and depth preference with changing temperature. Preferred depth increased and preferred velocity decreased with increasing temperature. Spawning RSFs for environmental variables may change as other environmental conditions (i.e., water temperature) change; thus, it is important to account for potential interactions when using or producing RSFs.

Résumé : En Amérique du Nord, des barrières infranchissables construites par les humains bloquent l'accès à des habitats de frai des salmonidés et nécessitent des efforts de restauration coûteux dans les habitats restants. Pour évaluer la qualité des habitats de frai restaurés, de l'information sur la vitesse dans l'eau et les profondeurs de prédilection des saumons, qui peuvent varier en fonction d'autres variables (p. ex. la température de l'eau), est nécessaire. Nous faisons la démonstration d'une méthode peu coûteuse et généralisable pour obtenir et analyser ces données, qui combine des relevés aériens de nids de frai de saumons chinooks (Oncorhynchus tshawytscha) de la migration hivernale, la modélisation hydraulique en 2D et des modèles linéaires généralisés pour calculer des fonctions de sélection des ressources (FSR) de frai. Notre méthode permet d'examiner les effets d'interactions entre différentes variables environnementales, souvent traitées comme étant indépendantes, sur la sélection d'habitats. Elle produit une FSR qui montre les interactions entre la vitesse et la profondeur de prédilection en fonction de la température. La profondeur de prédilection augmente et la vitesse de prédilection diminue quand la température augmente. Puisque les FSR de frai pour des variables environnementales peuvent changer en fonction des variations d'autres conditions ambiantes (c.-à-d. la température de l'eau), les interactions potentielles doivent être prises en considération lors de l'utilisation ou de la production de FSR. [Traduit par la Rédaction]
\end{abstract}

\section{Introduction}

Decisions species make about habitat selection are crucial for their fitness, and understanding these decisions is critical for management. One of the most important, and often final, decisions a female salmonid makes is where to deposit her eggs. This is a complex decision, as her eggs must survive numerous threats throughout the incubation period for her genes to enter the next generation. Her eggs and alevins (young fry) must avoid oxygen depletion, de-watering, overheating, freezing, predation, pathogens, scouring, and superimposition. To reduce the risk of these threats when selecting a spawning location, spawners must consider a variety of environmental characteristics that affect reproductive success, such as gravel size, geomorphology, hydraulics, and aquatic vegetation (Crisp and Carling 1989; Merz et al. 2008; Moir and Pasternack 2008). Among these, two key characteristics that greatly affect the risks posed by these threats are water velocity and depth (Groves and Chandler 1999).
Our understanding of the velocity and depth values salmonids prefer for spawning is important for ecological modeling and restoration actions. This information can help guide spawning gravel augmentation (Campos et al. 2014) or the engineering of spawning focused side channel restoration (e.g., Glenn-Colusa Irrigation District 2014). Management-focused models also use these relationships to simulate spawning behavior (Dudley, 2019). Measuring these velocity and depth preferences is complicated, as salmonids make velocity and depth selections amid numerous other environmental factors that are dynamic, changing spatially across systems, and temporally within systems. Salmonid velocity and depth preferences are salmon run- and system-specific (e.g., Smith 1973; McHugh and Budy 2004), and may also be specific to current environmental conditions. Thus, when calculating velocity and depth preferences, scientists may need to account for potential interactions with other environmental variables, which may have important management implications. One likely important confounding variable is temperature, which affects egg development

Received 27 January 2021. Accepted 8 May 2021.

P.N. Dudley, S.N. John, and M.E. Daniels. Fisheries Collaborative Program, University of California, Santa Cruz, California, USA; Southwest Fisheries Science Center, National Marine Fisheries Service, Santa Cruz, California, USA.

E.M. Danner. Southwest Fisheries Science Center, National Marine Fisheries Service, Santa Cruz, California, USA.

Corresponding author: Peter N. Dudley (email: peter.dudley@noaa.gov).

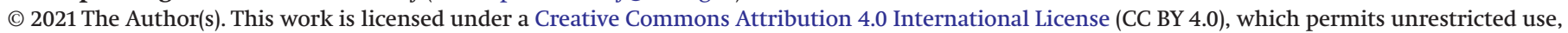
distribution, and reproduction in any medium, provided the original author(s) and source are credited. 
and survival both directly and indirectly through many other factors. We hypothesize that spawners experiencing higher temperatures would seek deeper, faster water. We hypothesize that this water may be cooler, and the faster, cooler water may deliver more oxygen to the eggs.

Knowledge of these preferences for management decisions is especially important, as many salmonids, like many species, occupy fragmented landscapes. Dams are frequently the cause of this habitat fragmentation. Because dam operations control the timing and volume of water released, they can control velocity and depth profiles downstream. In addition, many large dams (e.g., Glen Canyon Dam on the Colorado River, Cougar Dam on the McKenzie River, Shasta Dam on the Sacramento River, and Flaming Gorge Dam on the Green River) have temperature control devices that allow for selective withdrawal from thermally stratified reservoirs. Even dams without direct temperature control systems can have some control over river temperature through release timing and volume (Krause et al. 2005). Thus, depending on the system, managers have varying levels of control over flow (and extension velocity and depth) and temperature. Therefore, especially in regulated systems, it is crucial to know how these three variables affect spawning behavior. Establishing these interactions, however, can be laborand time-intensive; thus, there are significant benefits to determining these relationships using existing data.

To investigate potential interactions between temperature and spawning velocity or depth preference, and test a potential method that capitalizes on available data, we used the Sacramento River winter-run Chinook salmon (Oncorhynchus tshawytscha) (hereinafter "winter-run") in California's Central Valley as a case study. Since the 1940s, Keswick Dam, which creates the forebay to Shasta reservoir, has cut off winter-run from their historical spawning grounds. In 1994, the United States Federal Government listed winter-run as endangered, driving restoration, temperature and flow management, and modeling work that attempts to increase, improve, or assess spawning habitat (e.g., California Natural Resources Agency 2020; Dudley 2018).

In the Sacramento River, as with several large rivers with managed salmon populations, there are regular spawning season aerial surveys that record the locations and counts of redds (salmon nests) (Neilson and Geen 1981; Dauble and Watson 1997; Pipal 2005). If flow is known on the day a redd was observed, twodimensional (2D) hydraulic modeling (Hydrologic Engineering Center 2016) can simulate the water depth and velocity at each redd location. Additionally, temperature models can supply the water temperature for the date and location of the redd observation. From the combination of these two data sources, we can construct a resource selection function (RSF) (Manly et al. 1993) for spawning habitat. Unlike classic habitat suitability indices (HSIs), which may use expert opinion or other non-statistical methods, RSFs are constructed using animal presence data and statistical functions (Boyce et al. 2002). Long-running redd aerial surveys are a good data source for spawning RSFs, which require large animal count data sets that provide sufficient opportunities for animals to demonstrate their preferences.

One study on the use of spawning velocity and depth habitat of winter-run (Gard 2009) produced a high-quality data set. However, the methods (underwater video) were labor intensive, and the resulting redd counts were small $(\sim 226)$ compared to the aerial survey data. While measuring redd characteristics directly is more precise than using aerial surveys, small data sets gathered this way are unlikely to capture the full range of spawning site characteristics salmonids choose. In this paper, we combine multi-decade aerial redd surveys with historical flow data and 2D hydraulic modeling to develop winter-run spawning RSFs for depth and velocity. We then explore interactions between and
Fig. 1. The extent of winter-run redds from 1990-2017 and the portion of the river that constitutes the study area. The background map is California, USA. The thick black line is the Sacramento River, and smaller lines with a white dash are major roads for reference. Target marks denote various river confluences, structures, and towns. All winter-run redd sites were above Tehama, California. The bathymetry extended from Keswick Dam to the gray arrow on the river, which constituted the study area. Map produced with QGIS 3.4 (QGIS Development Team 2021). Base maps US Census Bureau, Geography Program (United States Census Bureau: Geography Program 2020).

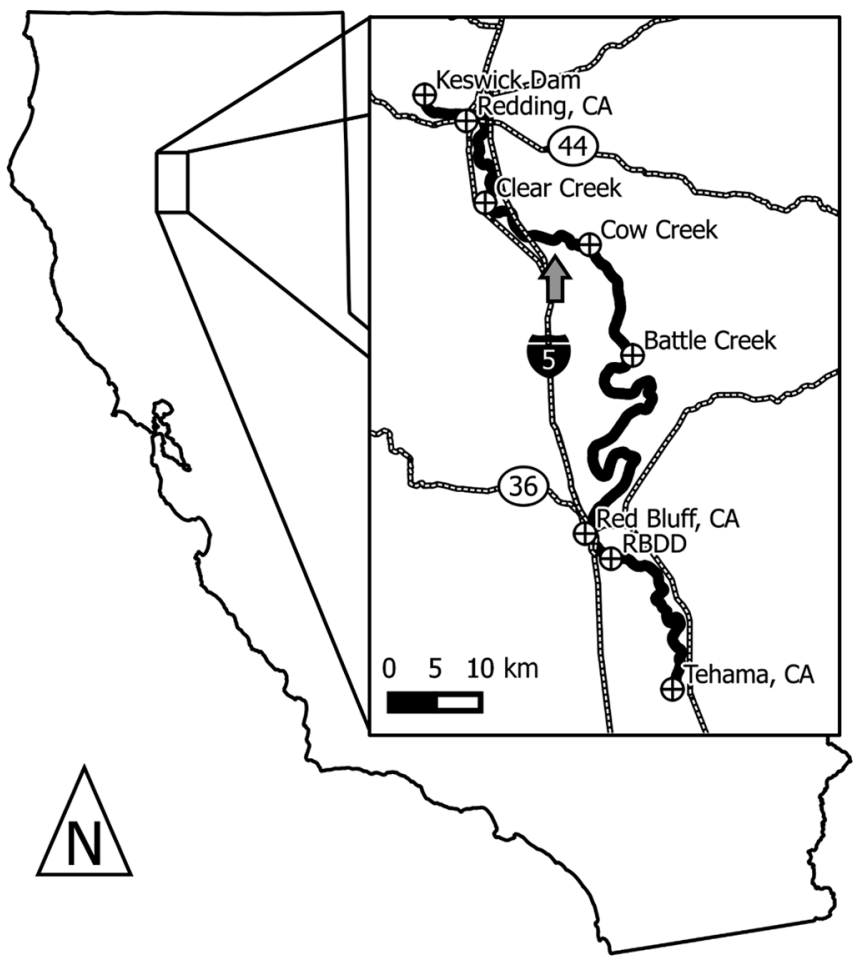

the effects of water temperature on these RSFs. Finally, we construct a tool to allow managers to visualize RSF results on the Sacramento River under specific flow conditions.

\section{Materials and methods}

\subsection{Redd location data}

The winter-run redd aerial survey takes place from mid-April to mid-August, averaging 12 surveys annually (Supplementary material S1 ${ }^{1}$ ) (Killam et al. 2014). The survey uses a helicopter to achieve a more accurate count compared to a fixed-wing aircraft. Trained observers marked spawning site locations on a map during each flight from 1990 to 2017 (Supplementary material S2 ${ }^{1}$ ). When clustered near each other, multiple redds are counted and represented as a single point location (hereinafter site) feature on the survey maps. We then georeferenced these locations in ArcGIS (Esri 2015), constructed a point layer by placing a point at the center of each marked spawning site, and assigned the relevant metadata. As the Sacramento River has regulated flows and the aerial surveys occur on a frequent basis (on average every 9.5 days), we assumed detection date conditions were representative of conditions when the spawner chose the site and created the redd. Winter-run redd observations on the Sacramento River extend from Keswick Dam to the C St. Bridge (73 river kilometres downstream) near Tehama, California (Fig. 1). 
Fig. 2. The areas over which the model distributes presence $(x)$ and absence (o) points. The model randomly distributes the presence points in the area of a circle $(D)$ centered on the center of the observer's mark $(\mathrm{M})$ with a radius equal to the estimated accuracy of the observation $(A)$ plus the radius $(R)$ of a redd cluster containing the number of redds reported $(n)$. The radius of the cluster of redds $(R)$ is equal to the area of a single redd $(a)$, times the number of observed redds $(n)$, divided by $\pi$, and square-rooted. Absence points are distributed in a grid over the model area and the model removes any that are inside any of the circles constructed around an observed redd point. [Colour online.]

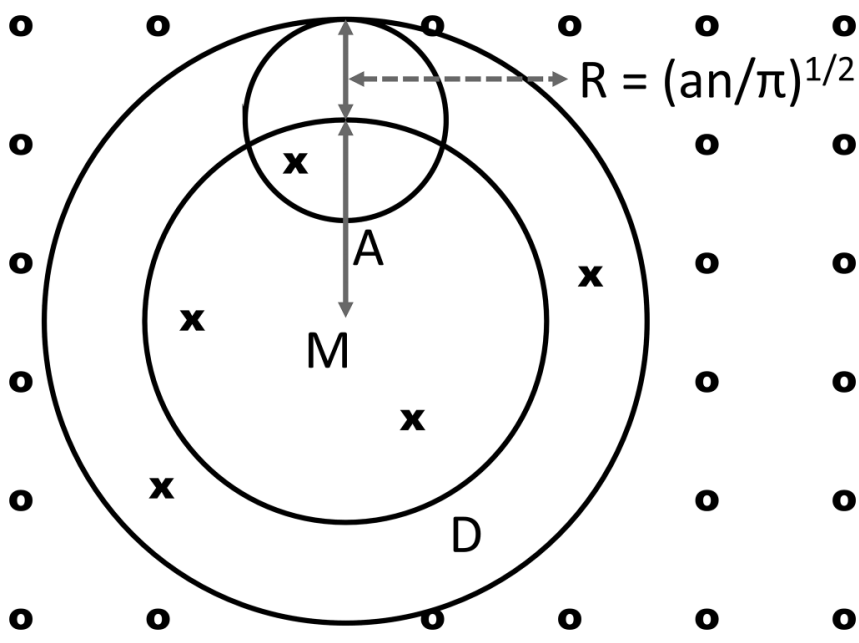

To account for both the error in the recorded location of each redd and the procedure of listing multiple redds at a single site, we created 200 different data sets and allowed the exact locations of the redds to vary between each set. Each set began with the same georeferenced redd point locations. We then constructed a circular buffer around each point with a radius of $36.5 \mathrm{~m}$. This estimate of accuracy comes from errors measured in helicopter surveys of plants that used similar map-based recordings of locations (Rebbeck et al. 2015). We increased the buffer radius by a distance equal to the radius of a circle of area equal to the area of a Chinook redd $\left(8.4 \mathrm{~m}^{2}\right)$ (Newton and Brown 2004; Gallagher and Gallagher 2005; Giovannetti and Brown 2008; Riebe et al. 2014) multiplied by the number of redds counted at the current site (Fig. 2). We then randomly distributed a number of points inside each circle equal to the redd count at that site. We used these randomly distributed points as the redd locations for the analysis. We repeated this procedure multiple times to construct 200 data sets.

To create points where redds were never observed across all survey years (absence points), we created a polygon of the wetted area of the Sacramento River at the typical flow during the winterrun spawning season $\left(300 \mathrm{~m}^{3} \cdot \mathrm{s}^{-1}\right.$ flow). We assumed this entire area was accessible for spawning; however, substrate composition may make some areas unusable. We placed 80000 uniformly distributed points over this polygon, resulting in a point spacing of $7.3 \mathrm{~m}$. We removed any of these points inside any of the circular buffers constructed around any redd site. This process resulted in a set of 37221 potential absence points. We used a unique random set of these absence points (equal to the number of presence points) in each of the 200 data sets (see below). While the presence points had creation dates based on observation dates, each absence point required a creation date to assign a flow (and thus a depth and velocity) and a temperature value. Each absence point was assigned the date of a unique presence point (i.e., no presence point's date was used twice).

\subsection{Modeled redd depth and velocity}

To determine velocity and depth at each point in the data set, we constructed a $2 \mathrm{D}$ hydraulic model using $0.5 \mathrm{~m}$ resolution sonar derived bathymetry from the US Bureau of Reclamation (Bradley and Greimann 2020). This bathymetry domain extended from Keswick Dam to $0.5 \mathrm{~km}$ upstream of the confluence with Cow Creek (Fig. 1). Because the majority of redd sightings (98.8\%) occurred within this domain, we ignored all redds downstream. We used this bathymetry along with the flow model HEC-RAS 2D (Hydrologic Engineering Center 2016) to create velocity and depth rasters for the Sacramento River within this domain. We used HECGeoRAS to adjust the bathymetry to account for the AndersonCottonwood Irrigation District Flashboard Dam in Redding. Our hydraulic model domain consisted of a $20 \mathrm{~m}$ resolution grid over the river channel. In computation, HEC-RAS 2D uses both the resolution of the domain grid and the resolution of the underlying raster $(0.5 \mathrm{~m})$ (high-resolution subgrid model; Casulli 2009). As our initial Manning's $N$ values, we used values from a previously calibrated 1 D HEC-RAS model of the Sacramento River. We ran calibration simulations by adjusting Manning's $N$ values until the wetted area of the river matched satellite imagery taken at known flows. We ran the model for values of flow from 50 to $800 \mathrm{~m}^{3} \cdot \mathrm{s}^{-1}$ by steps of $50 \mathrm{~m}^{3} \cdot \mathrm{s}^{-1}$ and from 800 to $2400 \mathrm{~m}^{3} \cdot \mathrm{s}^{-1}$ by steps of $200 \mathrm{~m}^{3} \cdot \mathrm{s}^{-1}$. We chose these values based on historical flow values during the winter-run spawning window (May-August). During this window from 1990 to 2017, 97\% of historical flow values were below $800 \mathrm{~m}^{3} \cdot \mathrm{s}^{-1}$, justifying the coarser resolution above $800 \mathrm{~m}^{3} \cdot \mathrm{s}^{-1}$. Each flow simulation resulted in two $0.5 \mathrm{~m}$ resolution rasters: one of water depth and one of vertically averaged water velocity. We assumed the minimum reasonable resolution for sampling redd site depths and velocities was equal to the diameter of a redd $(3.26 \mathrm{~m})$. Thus, for computational efficiency, we used cubic splines to rescale the rasters to a $3.26 \mathrm{~m}$ resolution.

We used the River Assessment for Forecasting Temperature (RAFT; Pike et al. 2013; Daniels et al. 2018) to assign flow and temperature values to redd locations based on the creation date. RAFT is a one-dimensional model that simulates river temperature and flow in the longitudinal direction. For this analysis, we ran RAFT on a daily time step with a $2 \mathrm{~km}$ spatial resolution. When reconstructing historical river temperatures, RAFT assimilates gauge data using a version of the ensemble Kalman filter to improve model performance (Evensen 2009) with root mean square errors often below $0.5^{\circ} \mathrm{C}$ (Pike et al. 2013; Daniels et al. 2018). Using the $2 \mathrm{~km}$ resolution RAFT data, we assigned each presence and absence point a flow and temperature based on its creation date and river kilometre. We then took the flow assigned to each point and performed a linear interpolation between the rasters created with HEC-RAS (both depth and velocity) to calculate the actual depth and velocity at that point on the creation date. This procedure resulted in a data set with velocity, depth, and temperature at each presence and absence point for their creation date. In some of the data sets there were rare absence points that were deeper than any presence point; we removed these as there is a higher probability that a redd there might be too deep for detection. We removed the small fraction $(\sim 1 \%)$ of presence points in each data set that were not wetted. Having equal number of presence and absence points can improve model predictive accuracy (Hattab et al. 2013), so in each of the 200 data sets, we used random sampling without replacement to reduce the number of absence points from more than 37000 available to a number equal to the number of presence points.

\subsection{Statistical models}

We conducted all statistical analyses using generalized linear models (GLMs) in R ( $\mathrm{R}$ Core Team 2015). The code used the dplyr and ggplot2 packages and was run using RStudio (RStudio Team 2015; Wickham 2016; Wickham et al. 2018). We conducted a quadratic logistic regression using a Bernoulli link function on velocity 
and depth separately to get RSFs for each. These models have the following form:

$$
\begin{aligned}
& S_{i} \sim \operatorname{Bernoulli}\left(p_{i}\right) \\
& E\left(S_{i}\right)=p_{i} \\
& \operatorname{logit}\left(p_{i}\right)=b_{0}+b_{1} x_{i}+b_{2} x_{i}^{2}
\end{aligned}
$$

In this model, $p_{i}$ is the probability of use for spawning $\left(S_{i}\right), b$ is the fitted parameter, and $x_{i}$ represents the value of the variable of interest at the $i$ th data point (either velocity or depth). The quadratic form allowed the RSF to be both peaked and asymmetrical. This shape was important because we expected the RSF to have an optimum value about which it need not be symmetrical.

Because temperature may interact with depth and velocity in site selection, we examined the effect of temperature using the following model:

$$
\begin{aligned}
& S_{i} \sim \operatorname{Bernoulli}\left(p_{i}\right) \\
& \begin{aligned}
& E\left(S_{i}\right)=p_{i} \\
& \operatorname{logit}\left(p_{i}\right)=b_{0}+b_{1} v_{i}+b_{2} v_{i}^{2}+b_{3} d_{i}+b_{4} d_{i}^{2}+ b_{5} T_{i}+b_{6} v_{i} d_{i} \\
&+b_{7} T_{i} v_{i}+b_{8} d_{i} T_{i}
\end{aligned}
\end{aligned}
$$

where $T_{i}, v_{i}$, and $d_{i}$ represent temperature, velocity, and depth values, respectively, for the $i$ th data point. We then checked whether either of the temperature interaction terms $\left(b_{7}\right.$ and $\left.b_{8}\right)$ were nonzero across the 200 data sets. As either velocity or depth may be correlated with temperature in this system, an apparent interaction between either velocity or depth and temperature on site selection could arise irrespective of winter-run behavior. To assess this potential, we fit an equation using only depth and velocity:

$$
\begin{aligned}
& S_{i} \sim \operatorname{Bernoulli}\left(p_{i}\right) \\
& E\left(S_{i}\right)=p_{i} \\
& \operatorname{logit}\left(p_{i}\right)=b_{0}+b_{1} v_{i}+b_{2} v_{i}^{2}+b_{3} d_{i}+b_{4} d_{i}^{2}+b_{5} v_{i} d_{i}
\end{aligned}
$$

We used this model to construct a simulated data set where selection of redd site location was only based on depth and velocity. For all presence and absence velocity, depth, and temperature data, we assigned them simulated presence or absence values probabilistically based on the velocity- and depth-derived RSF. We conducted the same multivariable analysis with temperature on this simulated data set, and compared the values for the interaction terms $\left(b_{7}\right.$ and $\left.b_{8}\right)$ from the actual and simulated data sets.

To check if visibility could be a confounding factor in assessing the relationship between temperature and depth, we took from the redd data set al. sightings where the spotter had recorded a visibility distance value. We conducted linear regression between temperature and depth in this data set. We then divided this data set into three data sets (low, medium, and high visibility), and conducted the same multivariable analysis with temperature on these data sets to see if there were similar results in each visibility category as compared to the complete data set.

After running the model described by eq. 2, we ran eight different models by removing combinations of interaction terms from eq. 2 . We checked the AIC of these eight models to decide on a single model for use in a visualization tool of spawning habitat. To evaluate the predictive power of the selected most parsimonious model (the model with the lowest AIC) and conducted a 4-fold partitioning of each data set by dividing our data sets into four groups, using three to calibrate the model, and the remaining fourth to test the model. This method resulted in 800 tests of the model from which we constructed receiver operator curves (ROCs) and calculated the area under the curve (AUC) for each (Murtaugh 1996; Fielding and Bell 1997; Boyce et al. 2002).

To check for spatial correlation, we examined a variogram of the residuals from our model. We then divided the river into segments to remove spatial correlation (2 segments were sufficient to remove spatial correlation) and ran a generalized linear mixed
Fig. 3. The density plots of depths (A) and velocities (B) where winter-run redds were present (blue: positive density plot) and absent (red: negative density plot), the 200 RSF GLM fits (partially transparent black lines), and the highest and lowest values of the 95\% confidence intervals (CIs) from any of the 200 GLMs (dotted black line). [Colour online.]
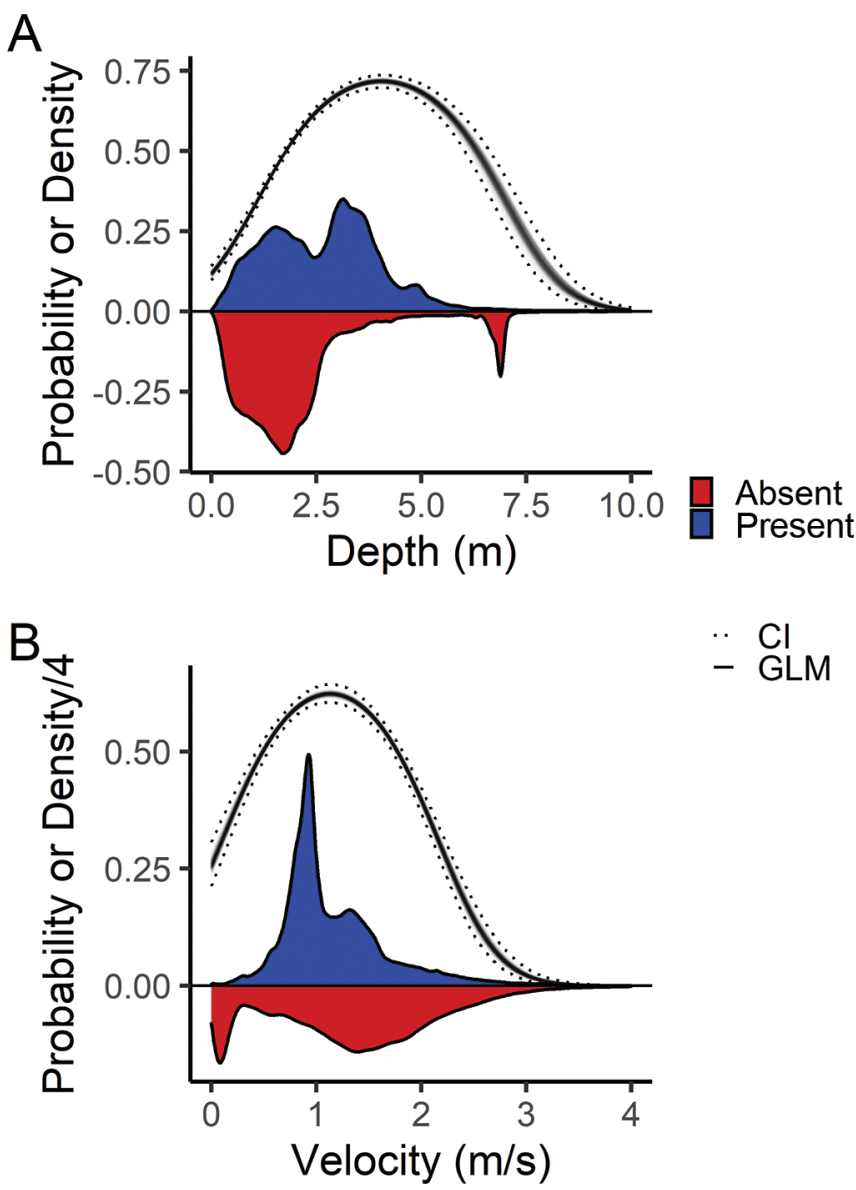

. $\mathrm{Cl}$ - GLM

model using the lme4 package in $\mathrm{R}$ (Bates et al. 2015) with river section as a random effect to compare to our non-spatial model.

Finally, we constructed a Shiny application (RStudio 2013) using the mean coefficients of the lowest AIC model to show RSF values for a user-selected section of the Sacramento River given a user-selected flow and temperature, which is applied over the entire domain of interest. The application also allows users to change between metric and imperial units (to make it accessible to both scientists and US managers); visualize historical redd locations; map depth and velocity rasters; plot histograms of depth, velocity, and RSF values; save images; and download the velocity, depth, and RSF data.

\section{Results}

The final data sets contained an equal number (10 027 to 10113) of presence and absence points. All GLMs converged using R's stats::glm functions default convergence criteria (positive convergence tolerance $<1 \times 10^{-8}$ ). The RSF depth value peaked at $4.1 \mathrm{~m}$, which is deeper than the average depth of presence points $(2.7 \mathrm{~m}$, SD $1.4 \mathrm{~m}$; Fig. 3A). This difference is due to the smaller amount of available habitat at greater depths compared to the intense use of that deeper habitat (Fig. 3A). The RSF for velocity peaked at $1.13 \mathrm{~m} \cdot \mathrm{s}^{-1}$, while the mean velocity of presence data was $1.16 \mathrm{~m} \cdot \mathrm{s}^{-1}$ (SD $0.49 \mathrm{~m} \cdot \mathrm{s}^{-1}$; Fig. 3B). Mean parameter values are shown in eqs. 4 and 5. 
Fig. 4. The distribution of values of the depth (D) vs. temperature (T) (panel A) and velocity (V) vs. temperature (T) (panel C) interaction terms from the GLMs. The dashed lines are the extreme values of the 95\% CI from the 200 GLM. The relationship of the RSF vs. depth and temperature at a representative velocity of $1.48 \mathrm{~m} \cdot \mathrm{s}^{-1}$ (panel B) and RSF vs. velocity and temperature at a representative depth of $2.17 \mathrm{~m}$ (panel D). There are shifts in the maximum RSF value as temperature changes (dashed lines). For visualization purposes, the maximum RSF value is independently normalized to 1 at each temperature value. [Colour online.]
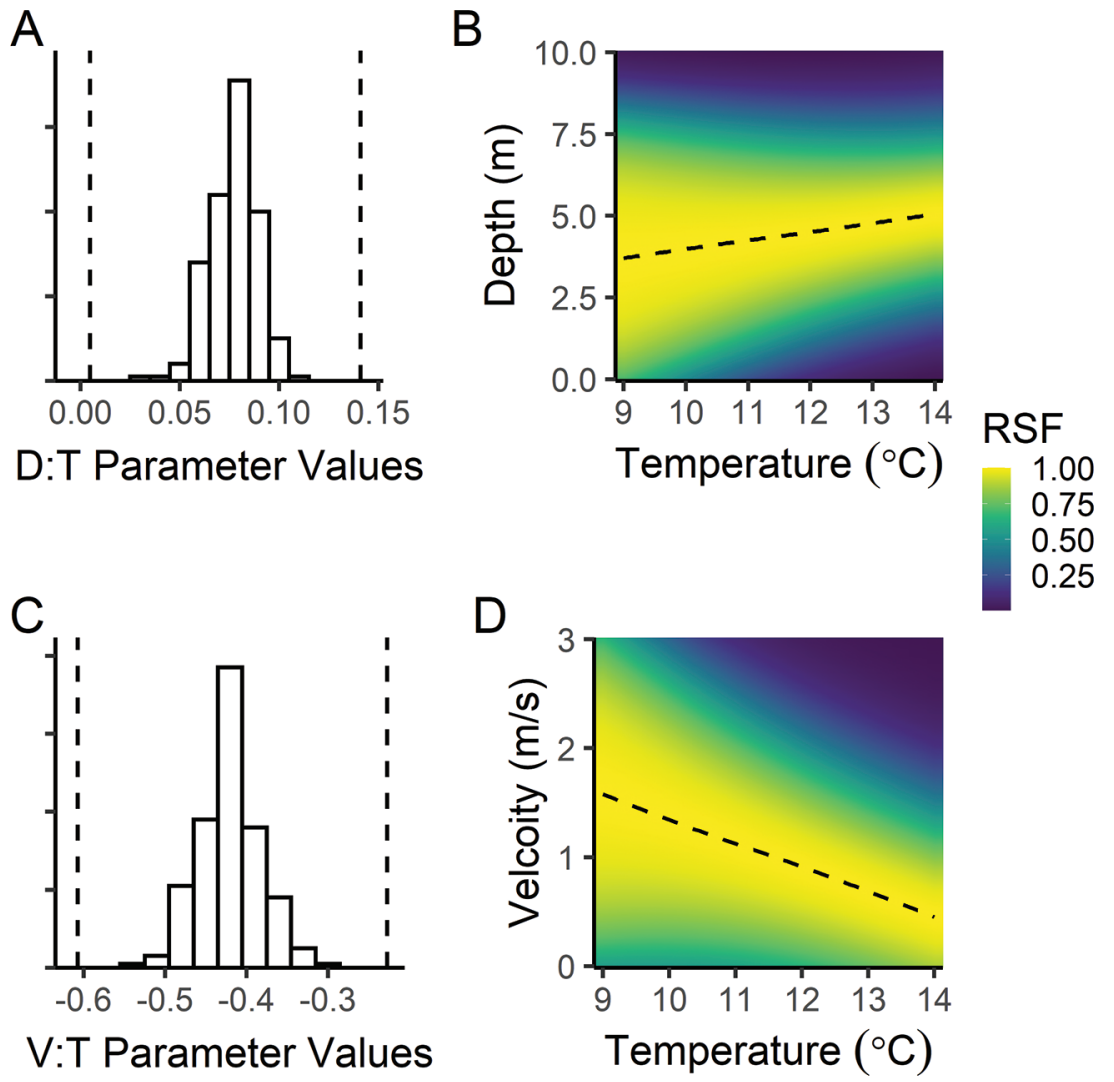

$$
\begin{aligned}
& S=\left[1+\mathrm{e}^{-\left(-2.02+1.46 d-0.18 d^{2}\right)}\right]^{-1} \\
& S=\left[1+\mathrm{e}^{-\left(-1.06+2.77 v-1.22 v^{2}\right)}\right]^{-1}
\end{aligned}
$$

For the model including temperature, all parameter estimates for the interaction term between temperature and depth were positive, and none of the $95 \%$ confidence interval $(\mathrm{CI})$ values overlapped with zero (Figs. 4A-4B). Similarly, all estimates for the interaction term between temperature and velocity were negative, and none of the $95 \%$ confidence interval (CI) values overlapped with zero (Figs. 4C-4D). Equation 6 shows the mean parameter values for this model. When using the simulated data, both distributions of these parameter values were centered on zero (Supplementary material S3 ${ }^{1}$ ). The visibility analysis showed that there is a slight increase in visibility as temperature increases, and that there is a consistent trend of optimum RSF depth increasing with temperature across all three levels of visibility (Supplementary material S4-S6 ${ }^{1}$ ).

(6) $\quad S=\left[1+\mathrm{e}^{-\left(2.13+6.53 v-0.93 v^{2}-0.25 d-0.15 d^{2}-0.384 T+0.095 v d-0.420 T v+0.077 d T\right)}\right]^{-1}$

Of the eight models under consideration for the management tool, we selected the model with the lowest AIC, which included interactions between temperature, depth, and velocity (Table 1). The 4-fold partitioning test of the most parsimonious model using ROC and the AUC metric resulted in AUCs from 0.78-0.82 (Supplementary material $\mathrm{S7}^{1}$ ). As temperature increases with

Table 1. The eight models under consideration for the management tool and their associated AIC and $\triangle$ AIC values.

\begin{tabular}{lllc}
\hline Interaction terms & No. of parameters & AIC & $\Delta$ AIC \\
\hline T:D, T:V, D:V & 9 & 22399 & 0 \\
T:V, D:V & 8 & 22418 & 19 \\
T:D, T:V & 8 & 22425 & 26 \\
T:V & 7 & 22442 & 43 \\
T:D, V:D & 8 & 22506 & 107 \\
T:D & 7 & 22524 & 125 \\
D:V & 7 & 22566 & 167 \\
None & 6 & 22588 & 189 \\
\hline
\end{tabular}

Note: The "Interaction Terms" column lists which interaction terms are included in each model. For example, the model listed with only "D:V" is eq. 3 in this manuscript, and the model with 9 parameters is eq. 2 in the manuscript. The model that included all the interaction terms was the most parsimonious. We tested additional models, including some without quadratic terms, but with various combinations of interaction terms. These other models all had high AIC values and are not presented here for simplicity.

constant values of depth and velocity, there is a reduction in the value of the RSF and a constriction of areas with higher values (Fig. 5). There is a clear constriction in the areas with high suitability as the temperature increases.

Dividing the river into upper and lower sections removed the spatial correlation seen across the whole modeling domain. While the GLMM produced different parameter estimates, it did not qualitatively change the findings of the non-spatial model (Supplementary material S8 ${ }^{1}$ ). 
Fig. 5. Velocity depth, and resource selection function value maps. The two RSF maps are for temperatures of 10 and $12^{\circ} \mathrm{C}$. The RSF values on each map are scaled to 1 to show the shift in relative habitat suitability independent of the absolute change. Map made using $\mathrm{R}$ ( $\mathrm{R}$ Core Team 2015) and associated packages (ggplot2 (Wickham 2016), patchwork (Pedersen 2019), and viridis (Garnier 2018)). [Colour online.]
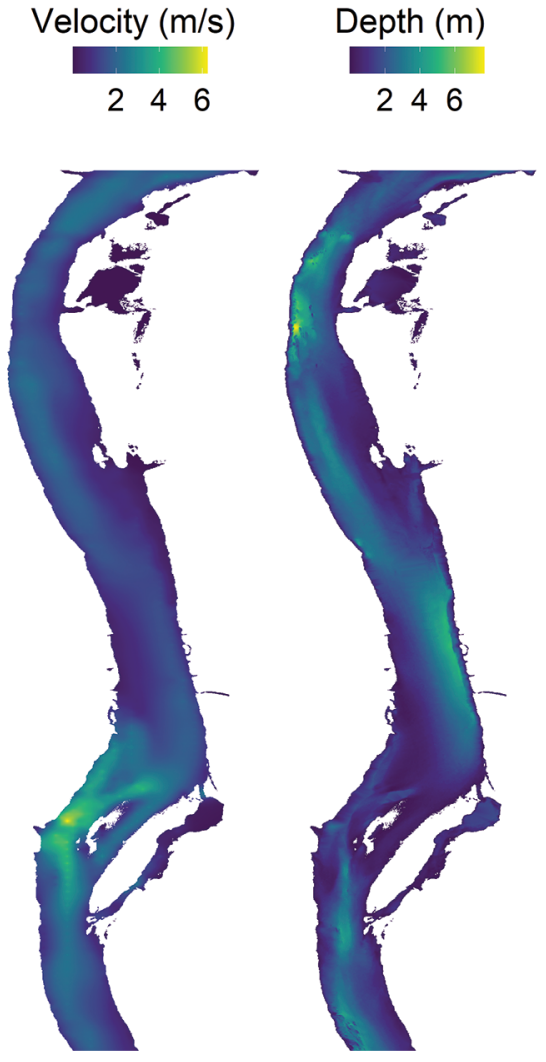

\section{Discussion}

Our RSFs indicate that the winter-run salmon prefer spawning in water that is $4.0 \mathrm{~m}$ deep with a velocity of $1.17 \mathrm{~m} \cdot \mathrm{s}^{-1}$, which is deeper but with a similar average velocity as the presence data on the Sacramento River, and that these depth and velocity preferences change with increasing temperature. In a multivariable RSF, we also found an interaction between temperature and depth, as well as between temperature and velocity. These interactions disappeared when using simulated data, indicating that they are not simply a result of correlations in available habitat. These findings indicate the importance of accounting for interacting environmental conditions when predicting salmon site selection, and that salmon may be using depth, velocity, and water temperature in combination to select spawning sites. These findings are particularly important on regulated rivers where managers have either direct or indirect control of water depth, velocity, and temperature. We found that the RSF with a first-order temperature component and interactions between temperature, depth, and velocity were the most parsimonious, using lowest AIC as the performance metric, and that the models performed well in out-of-sample prediction (AUCs between 0.79 and 0.82 ). For context, Boyce et al. (2002) classifies ecological models with AUCs between 0.7 and 0.9 as "useful applications" and those with greater values as having "high accuracy". Thus, we conclude that this modeling method likely provides value to managers when evaluating salmonid spawning.

There are many potential alternative methods to analyze this data, including a point process model and averaging environmental variables over areas around marked spawning sites. These two methods result in similar findings to the current method, that is, the optimum depth and velocity are similar, and as temperature
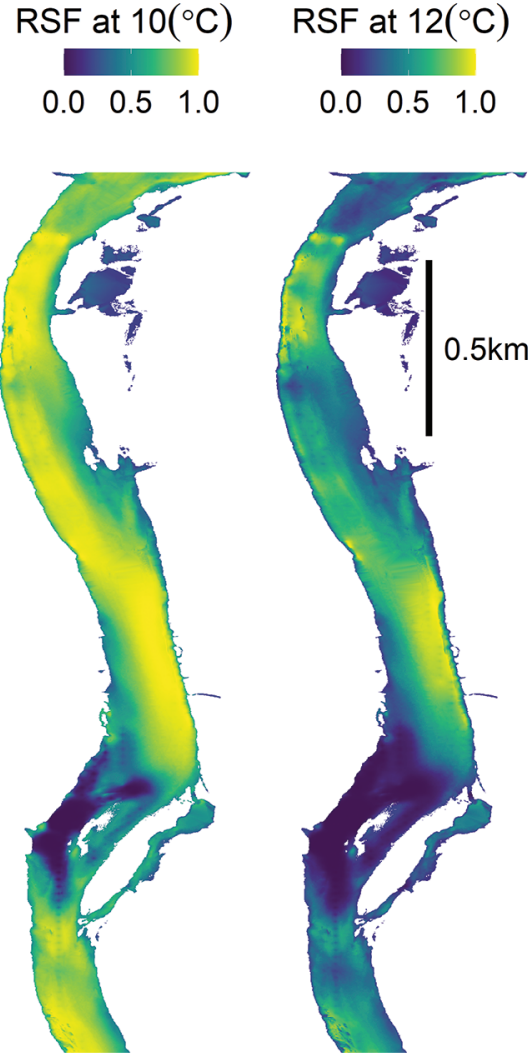

increases, the optimum depth increases while the optimum velocity decreases (Supplementary material S9-S15 ${ }^{1}$ ).

Sacramento River winter-run generally spawn deeper than most other populations of Chinook salmon, but the standard deviation of these depths overlaps with those spawning on large rivers (the Columbia and Snake rivers; Fig. 6A). Winter-run spawn in velocities at the approximate center of the range of velocities of other Chinook salmon populations (Fig. 6B). These data indicate that Chinook spawning site selection is either population- or habitat-specific or may be based on other factors not measured. Thus, managers should avoid applying outside population or run spawning site selection criteria to their system. In our specific case, we think this caution extends to considering the use of spawning habitat in winter-run inaccessible historical habitat above Shasta Dam. As temperature and flow conditions are quite different above Shasta Reservoir and on Battle Creek (winter-run historical habitat), we think that while the general interactions we have documented (e.g., decreasing depth with temperature) may be informative in these habitats, the values of the parameters of the RSF will likely differ. This opinion assumes some amount of plasticity or adaptability in the spawning habitat preferences of these fish, indicated by the variability in the data found in the literature (Fig. 6).

Water temperature is a significant factor in Chinook egg survival, providing one possible explanation for the positive depth preference with temperature. Evidence that deeper water may reduce temperature exposure is both direct (deeper redds are cooler) (Addley and Peterson 2011; Baxter and McPhail 1999) and indirect (some rivers experience thermal stratification in pools) (Adebisi 1981; Matthews et al. 1994; Turner and Erskine 2005; Becker et al. 2010; Butler and Hunt 2013). However, spawning deeper may expose redds to low-oxygenated upwelling water 
Fig. 6. The spawning depths (A) and velocities (B) used by other populations of Chinook salmon. The point is the mean, and bars represent the standard deviation. Points with no bars are from sources where standard deviations were unavailable and incalculable. Shape indicates the river and colour indicates the run. The arrow marks the current work. Numbers correspond to different data sets (see the Supplementary material $\mathrm{S} 16^{1}$ for list of study citations). [Colour online.]

A

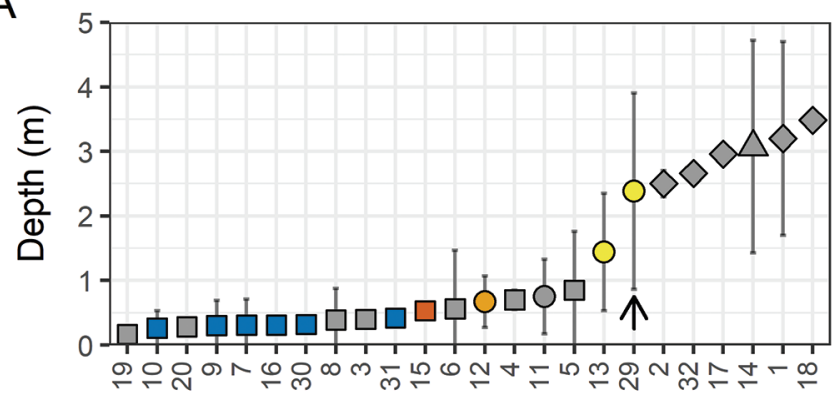

B

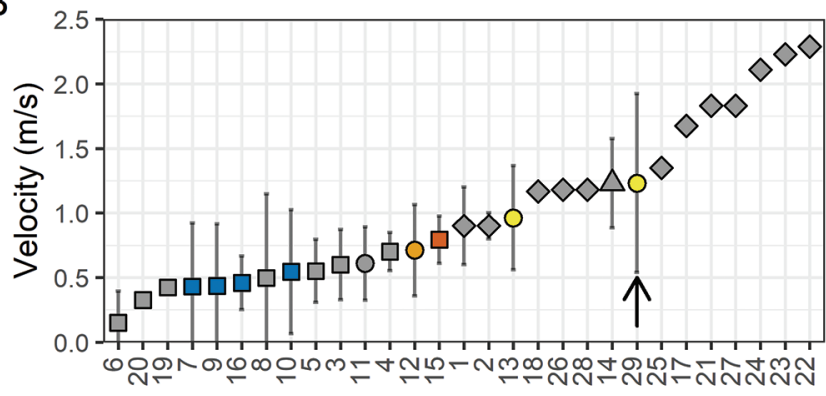

Run

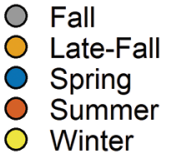

River

$\diamond$ Columbia

Other

Sacramento

$\triangle$ Snake
(Youngson et al. 2004). The negative relationship between velocity preference and temperature could be in response to increased metabolic costs associated with increasing temperatures. Alternatively, as velocity affects the size of gravel present in a location (Coleman and Smart 2011), winter-run may not be changing velocity preference with temperature, but instead may be selecting gravels of different grain sizes with increasing temperature; however, we are unaware of any literature showing any such response.

We examined the potential trade-off between increased temperature, reduced velocity, and metabolic rate by using an equation for respiration from the Wisconsin Fish Bioenergetics Model (Van Winkle et al. 1996; Hanson et al. 1997) with model parameters from the literature (Brocksen and Bailey 1973; Rombough and Ure 1991; Cech and Myrick 1999; Geist et al. 2003; Thorarensen and Farrell 2006). As the maximum velocity RSF changes with temperature, we calculated the relationship between the time spent swimming and the fraction of bulk velocity experienced when swimming that will maintain a constant metabolic rate (Fig. 7; Supplementary material $S 17^{1}$ ). We assumed a spawner can find refuge from the average velocity by both reducing the amount of time spent swimming or swimming in an area with lower than average velocity. As the fish can take both the above actions to different extents, the combinations of the amount of time spent swimming and the fraction of bulk velocity experienced will produce a curve. For a change in velocity and temperature equal to that change shown in the shifting maximum of the velocity RSF with changing temperature, any set of values on this curve will result in no change in total respiration.

Our RSF has direct applications to both water and salmonid management. Both the single variable and multivariable RSF can inform managers about the velocities and depths winter-run preferentially seek for spawning habitat. This work also shows how these RSFs, and likely spawning RSFs for other salmonids, may change as other environmental conditions (i.e., water temperature) change, highlighting the importance of accounting for potential interactions when using or producing RSFs. Our RSF
Fig. 7. The relationship between values of the fraction of bulk velocity experienced by the spawner (velocity fraction) and the fraction of time spent swimming (time fraction) that would result in the spawner's respiration remaining constant over the observed change in the velocity at which the RSF is maximum with temperature.

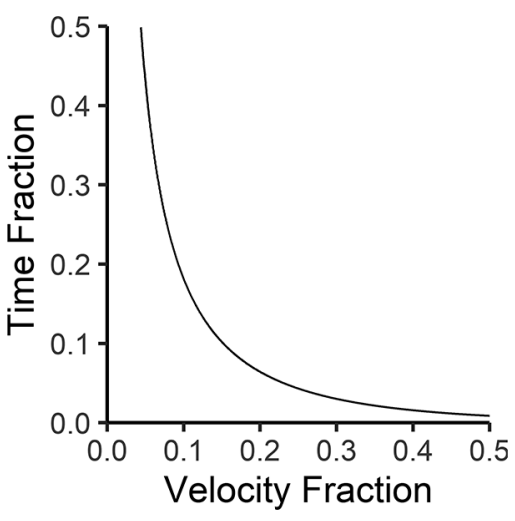

can aid managers in selecting the location of, and the optimal approach to spawning habitat focused restoration. These results must be considered along with the multitude of other factors that managers must consider when restoring habitat, including geomorphic concerns.

Spawning habitat needs are only one of multiple ways in which flow and temperature affect a salmon population. When managers have control over temperature and flow, as they do on the Sacramento River, water and natural resource management agencies will need to consider each of these effects and set management priorities based on the best available science. Managers should consider how flow and temperature will be regulated in the future when planning and assessing spawning habitat 
alteration actions. To aid managers in accessing information on winter-run RSF, we have developed a Shiny application (pndphd. shinyapps.io/WRRSF/; Supplementary material S18 ${ }^{1}$ ). We hope managers will use this application to see how RSF values change under different conditions and take this information into consideration when planning actions to increase spawning habitat through gravel augmentation or other geomorphic habitat changes.

RSF development and associated work could benefit from additional fine-scale temperature data collection, which would allow RSF to consider fine-scale thermal heterogeneity, as well as regular bathymetric surveys to detect geomorphic changes. This work would also benefit from knowledge of the gravel distribution on the river. A comprehensive gravel survey over the spawning area would permit absence points to be filtered to only those with appropriate gravel, which would give more credence to their avoidance based on velocity and depth. While there have been past gravel surveys, they are not of sufficient detail or extent to be of use in this analysis.

There are some caveats to our findings. We were not able to consider other habitat attributes that may have effects on the RSF, including geomorphic features such as pool tails or riffle crest (Moir and Pasternack 2008; Bradford et al. 2009), hyporheic exchange (but see Benjankar et al. 2016), and gravel presence or grain size. The use of bathymetry from a single year to analyze spawning preference over multiple years may have introduced model error due to changing channel morphology. Channel morphology could have changed for several reasons, including deliberate additions of gravel, gravel mobilization, and scour. However, there was little difference in elevation between the current (2017-2018) sonar data and survey points taken by the US Army Corps of Engineers in 2001 (Supplementary material S91). The areas with the largest changes are areas with low or no redd sightings, including immediately below Keswick Dam, in Turtle Bay, at a scour site near river kilometre 470 (Supplementary material $\mathrm{S}_{20}{ }^{1}$, Frame 7), and at a constriction at river kilometre 460 (Supplementary material S20 ${ }^{1}$, Frame 12). Finally, aerial surveys may have a limited ability to detect deep redds, resulting in underrepresentation of the tail of the depth distribution. However, our depth-use distribution is consistent with Chinook salmon spawning on other large rivers.

In summary, we demonstrated a method that can produce RSFs for spawning salmonids using aerial redd surveys, 2D hydraulic models, and logistic regression. We revealed important interactions between depth and velocity RSFs and a key environmental variable, water temperature. We made this RSF and more detailed information available through a web-based application for managers to use in assessing actions involving spawning habitat.

\section{Authors' contributions}

PD conceived the idea and all authors designed methodology; SJ digitized the redd location data; MD generated the RAFT data; PD analyzed the data; and PD led the writing of the manuscript. All authors contributed critically to the drafts and approved the final manuscript for publication.

\section{Data availability statement}

Data available from the Dryad Digital Repository https://doi. org/10.7291/D1SD4D (Dudley 2020).

\section{Acknowledgements}

We thank Shawn Mayr and Todd Hillarie of CDWR for providing survey-derived Sacramento River bathymetry, Doug Killam at CDFW for providing redd maps, Blair Greimann for providing the bathymetry, David Boughton for providing interval review, three anonymous reviewers and Michael Beakes for excellent feedback through peer review, and the US Bureau of Reclamation for funding.

\section{References}

Addley, R.C., and Peterson, N.P. 2011. Lower Spokane River redband trout spawning habitat: Monroe Street Dam to Nine Mile Dam pool. Spokane River Hydroelectric Project FERC Project No. 2545. Avista Corp., Spokane, Wash.

Adebisi, A.A. 1981. The physico-chemical hydrology of a tropical seasonal riverupper Ogun river. Hydrobiologia, 79(2): 157-165. doi:10.1007/BF00006123.

Bates, D., Mächler, M., Bolker, B., and Walker, S. 2015. Fitting linear mixedeffects models using \{lme4\}. J. Stat. Softw. 67(1): 1-48. doi:10.18637/jss. v067.i01.

Baxter, J.S., and McPhail, J.D. 1999. The influence of redd site selection, groundwater upwelling, and over-winter incubation temperature on survival of bull trout (Salvelinus confluentus) from egg to alevin. Can. J. Zool. 77(8): 1233-1239. doi:10.1139/z99-090.

Becker, A., Kirchesch, V., Baumert, H.Z., Fischer, H., and Schol, A. 2010. Modeling the effects of thermal stratification on the oxygen budget of an impounded river. River Res. Appl. 26: 572-588. doi:10.1002/rra.1260.

Benjankar, R., Tonina, D., Marzadri, A., McKean, J., and Isaak, D.J. 2016. Effects of habitat quality and ambient hyporheic flows on salmon spawning site selection. J. Geophys. Res. Biogeosci. 121(5): 1222-1235. doi:10.1002/ 2015JG003079.

Boyce, M.S., Vernier, P.R., Nielsen, S.E., and Schmiegelow, F.K.A. 2002. Evaluating resource selection functions. Ecol. Modell. 157(2-3): 281-300. doi:10.1016/ S0304-3800(02)00200-4

Bradford, M., Tonina, D., and Buffington, J.M. 2009. A three-dimensional model for analyzing the effects of salmon redds on hyporheic exchange and egg pocket habitat. Can. J. Fish. Aquat. Sci. 66(12): 2157-2173. doi:10.1139/F09-146.

Bradley, D.N., and Greimann, B. 2020. Technical Report No. ENV-2020-060: Sacramento River Gravel Augmentation Study. Available from https://www. sacramentoriver.org/forum/publications/side_channels/SacramentoRiverGravel BudgetReport_Final_508.pdf.

Brocksen, R.W., and Bailey, H.T. 1973. Respiratory response of juvenile chinook salmon and striped bass exposed to benzene, a water soluble component of crude oil. Am. Pet. Inst. Publ. 1973: 783-792. doi:10.7901/2169-3358-1973-1-783.

Butler, N.L., and Hunt, J.R. 2013. Characterization of pool thermal stratification in the San Joaquin River system. Am. Geophys. Union, Fall Meet. 2013.

California Natural Resources Agency. 2020. California Ecorestore Highlights. Sacramento. Available from https://water.ca.gov/PROGRAMS/ALL-PROGRAMS/ ECORESTORE.

Campos, C., Givens, D., and Massa, D. 2014. Redd monitoring and mapping in the Englebright Dam reach of the lower Yuba River, CA: summary report. Sacramento. Available from http://pasternack.ucdavis.edu/application/files/7213/7702/ 6270/USACE_EDR_ReddReport_20122013.pdf.

Casulli, V. 2009. A high-resolution wetting and drying algorithm for free-surface hydrodynamics. Int. J. Numer. Methods Fluids, 60: 391-408. doi:10.1002/ fld.1896.

Cech, J.J., Jr., and Myrick, C.A. 1999. Steelhead and Chinook salmon bioenergetics: temperature, ration, and genetic effects. Technical Completion Report (Project Number UCAL-WRC-W-885). Davis.

Coleman, S.E., and Smart, G.M. 2011. Fluvial sediment-transport processes and morphology. J. Hydrol. N.Z. 50(1): 37-58.

Crisp, D.T., and Carling, P.A. 1989. Observations on siting, dimensions and structure of salmonid redds. J. Fish Biol. 34(1): 119-134. doi:10.1111/j.10958649.1989.tb02962.x.

Daniels, M.E., Sridharan, V.K., John, S.N., and Danner, E.M. 2018. NOAA Technical Memorandum NMFS: Calibration and validation of linked water temperature models for the linked water temperature models for the Shasta Reservoir and the Sacramento River from 2000 to 2015. doi:10.7289/V5/TM-SWFSC-597.

Dauble, D.D., and Watson, D.G. 1997. Status of fall chinook salmon populations in the mid-Columbia River, 1948-1992. N. Am. J. Fish. Manage. 17(2): 283-300. doi:10.1577/1548-8675(1997)017<0283:SOFCSP $>2.3$.CO;2.

Dudley, P.N. 2018. A salmonid individual-based model as a proposed decision support tool for management of a large regulated river. Ecosphere, 9(1): e02074. doi:10.1002/ecs2.2074.

Dudley, P.N. 2019. S4: a spatially continuous, individual-based model of salmonid redd superimposition. Trans. Am. Fish. Soc. 148: 352-372. doi:10.1002/ tafs.10139.

Dudley, P.N. 2020. Winter-run Chinook salmon resource selection function 2020. UC Santa Cruz. 2020. doi:10.7291/D1SD4D.

Esri. 2015. ArcGIS Desktop. Environmental Systems Research Institute, Redlands, Calif.

Evensen, G. 2009. Data assimilation: the ensemble Kalman filter. 2nd ed. Springer Science \& Business Media, Heidelberg.

Fielding, A.H., and Bell, J.F. 1997. A review of methods for the assessment of prediction errors in PB models. Environ. Conserv. 24(1): 38-49. doi:10.1017| S0376892997000088. 
Gallagher, S.P., and Gallagher, C.M. 2005. Discrimination of chinook salmon, coho salmon, and steelhead redds and evaluation of the use of redd data for estimating escapement in several unregulated streams in Northern California. N. Am. J. Fish. Manage. 25(1): 284-300. doi:10.1577/ M04-016.1.

Gard, M. 2009. Comparison of spawning habitat predictions of PHABSIM and River2D models. Int. J. River Basin Manage. 7(1): 55-71. doi:10.1080/ 15715124.2009.9635370.

Garnier, S. 2018. viridis: default color maps from "matplotlib". Available from https://cran.r-project.org/package=viridis.

Geist, D.R., Brown, R.S., Cullinan, V.I., Mesa, M.G., Vanderkooi, S.P., and McKinstry, C.A. 2003. Relationships between metabolic rate, muscle electromyograms and swim performance of adult Chinook salmon. J. Fish Biol. 63(4): 970-989. doi:10.1046/j.1095-8649.2003.00217.x.

Giovannetti, S., and Brown, M.R. 2008. Adult spring Chinook salmon monitoring in Clear Creek, California: 2007 Annual Report. (September).

Glenn-Colusa Irrigation District. 2014. Initial study and mitigated negative declaration: Painter's Riffle Anadromous Fish Habitat Enhancement Project. Glenn-Colusa Irrigation District, Willows, Calif.

Groves, P.A., and Chandler, J.A. 1999. Spawning habitat used by fall chinook salmon in the Snake River. N. Am. J. Fish. Manage. 19(4): 912-922. doi:10.1577| 1548-8675(1999)019<0912:SHUBFC > 2.0.CO;2.

Hanson, P.T., Johnson, T., Kitchell, J., and Schindler, D.E. 1997. Fish bioenergetics 3.0. University of Wisconsin Sea Grant Institute, Madison.

Hattab, T., Ben Rais Lasram, F., Albouy, C., Sammari, C., Romdhane, M.S., Cury, P., et al. 2013. The use of a predictive habitat model and a fuzzy logic approach for marine management and planning. PLoS ONE, 8(10): e76430. doi:10.1371/journal.pone.0076430. PMID:24146867.

Hydrologic Engineering Center. 2016. Hydrologic Engineering Center's River Analysis System. Hydrologic Engineering Center.

Killam, D., Johnson, M., and Revnak, R. 2014. Chinook salmon populations of the Upper Sacramento River Basin in 2014. RBFO Technical Report No. 03-2015, State of California The Natural Resources Agency, Sacramento.

Krause, C.W., Newcomb, T.J., and Orth, D.J. 2005. Thermal habitat assessment of alternative flow scenarios in a tailwater fishery. River Res. Appl. 21(6): 581-593. doi:10.1002/rra.829.

Manly, B.F.J., McDonald, L.L., and Thomas, D.L. 1993. Resource selection by animals: statistical design and analysis for field studies. Chapman \& Hall, London.

Matthews, K.R., Berg, N.H., Azuma, D.L., and Lambert, T.R. 1994. Cool water formation and trout habitat use in a deep pool in the Sierra Nevada, California. Trans. Am. Fish. Soc. 123(4): 549-564. doi:10.1577/1548-8659(1994) $123<0549$ :CWFATH $>2.3$.CO; 2 .

McHugh, P., and Budy, P. 2004. Patterns of spawning habitat selection and suitability for two populations of spring Chinook salmon, with an evaluation of generic versus site-specific suitability criteria. Trans. Am. Fish. Soc. 133(1): 89-97. doi:10.1577/t03-021.

Merz, J.E., Smith, J.R., Workman, M.L., Setka, J.D., and Mulchaey, B. 2008. Aquatic macrophyte encroachment in Chinook salmon spawning beds: lessons learned from gravel enhancement monitoring in the Lower Mokelumne River, California. N. Am. J. Fish. Manage. 28(5): 1568-1577. doi:10.1577| M07-043.1.

Moir, H.J., and Pasternack, G.B. 2008. Relationships between mesoscale morphological units, stream hydraulics and Chinook salmon (Oncorhynchus tshawytscha) spawning habitat on the Lower Yuba River, California. Geomorphology, 100: 527-548. doi:10.1016/j.geomorph.2008.02.001.

Murtaugh, P.A. 1996. The statistical evaluation of ecological indicators. Ecol. Appl. 6(1): 132-139. doi:10.2307/2269559.

Neilson, J.D., and Geen, G.H. 1981. Enumeration of spawning salmon from spawner residence time and aerial counts. Trans. Am. Fish. Soc. 110(4): 554-556. doi:10.1577/1548-8659(1981)110<554:EOSSFS > 2.0.CO;2.
Newton, J.M., and Brown, M.R. 2004. Adult spring Chinook salmon monitoring in Clear Creek, California 1999-2002. US Fish and Wildlife Service, Red Bluff, Calif.

Pedersen, T.L., 2019. patchwork: the composer of plots. Available from https:/ cran.r-project.org/package $=$ patchwork

Pike, A., Danner, E., Boughton, D., Melton, F., Nemani, R., Rajagopalan, B., and Lindley, S.T. 2013. Forecasting river temperatures in real time using a stochastic dynamics approach. Water Resour. Res. 49(9): 5168-5182. doi:10.1002/ wrcr.20389.

Pipal, K.A. 2005. Summary of monitoring activities for ESA-listed salmonids in California's Central Valley. NOAA Tech. Memo. NMFS-SWFSC 373(March).

QGIS Development Team. 2021. QGIS Geographic Information System. Open Source Geospatial Foundation Project. Available from http://qgis.osgeo. org.

R Core Team. 2015. R: a language and environment for statistical computing. R Foundation for Statistical Computing, Vienna, Austria. Available from www.R-project.org.

Rebbeck, J., Kloss, A., Bowden, M., Coon, C., Hutchinson, T.F., Iverson, L., and Guess, G. 2015. Aerial detection of seed-bearing female Ailanthus altissima: a cost-effective method to map an invasive tree in forested landscapes. For. Sci. 61(6): 1068-1078. doi:10.5849/forsci.14-223.

Riebe, C.S., Sklar, L.S., Overstreet, B.T., and Wooster, J.K. 2014. Optimal reproduction in salmon spawning substrates linked to grain size and fish length. Water Resour. Res. 50: 898-821. doi:10.1002/2013WR014231.

Rombough, P.J., and Ure, D. 1991. Partitioning of oxygen uptake between cutaneous and branchial surfaces in larval and young juvenile Chinook salmon Oncorhynchus tshawytscha. Physiol. Zool. 64(3): 717-727. doi:10.1086| physzool.64.3.30158203.

RStudio. 2013. Easy web applications in R. RStudio, Inc. Available from https://shiny.rstudio.com/.

RStudio Team. 2015. RStudio: integrated development for R. RStudio, Inc., Boston. Available from http://www.rstudio.com/.

Smith, A.K. 1973. Development and application of spawning velocity and depth criteria for Oregon salmonids. Trans. Am. Fish. Soc. 102: 312-316. doi:10.1577/1548-8659(1973)102<312:DAAOSV > 2.0.CO;2.

Thorarensen, H., and Farrell, A.P. 2006. Postprandial intestinal blood flow, metabolic rates, and exercise in Chinook salmon (Oncorhynchus tshawytscha). Physiol. Biochem. Zool. 79(4): 688-694. doi:10.1086/505512. PMID:16826495.

Turner, L., and Erskine, W.D. 2005. Variability in the development, persistence and breakdown of thermal, oxygen and salt stratification on regulated rivers of southeastern Australia. River Res. Appl. 21(2-3): 151-168. doi:10.1002/rra.838.

United States Census Bureau: Geography Program. 2020. TIGER/Line Shapefiles. Available from https://www.census.gov/geographies/mapping-files/time-series/ geo/tiger-line-file.html [accessed 6 July 2020].

Van Winkle, W., Jager, H.I., Railsback, S.F., Holcomb, B.D., Studley, T.K., and Baldrige, J.E. 1998. Individual-based model of sympatric populations of brown and rainbow trout for instream flow assessment: model description and calibration. Ecol. Modell. 110(2): 175-207. doi:10.1016/S0304-3800 (98)00065-9.

Wickham, H. 2016. ggplot2: elegant graphics for data analysis. Springer-Verlag, New York. Available from https://ggplot2.tidyverse.org.

Wickham, H., François, R., Henry, L., and Müller, K. 2018. dplyr: a grammar of data manipulation. Available from https://cran.r-project.org/package= dplyr.

Youngson, A.F., Malcolm, I.A., Thorley, J.L., Bacon, P.J., and Soulsby, C. 2004. Long-residence groundwater effects on incubating salmonid eggs: Low hyporheic oxygen impairs embryo development. Can. J. Fish. Aquat. Sci. 61(12): 2278-2287. doi:10.1139/f04-217. 